\title{
High incidence of glucose intolerance in Vogt-Koyanagi-Harada disease
}

Nobuyo Yawata, Satoshi Nakamura, Masaya Kijima, Nakako Ikai, Mitsuyo Kanai, Miyuki Sugita, Shigeaki Ohno

\begin{abstract}
Aims-To evaluate glucose tolerance of patients with Vogt-Koyanagi-Harada (VKH) disease before systemic corticosteroid therapy, and to assess changes brought on by treatment.

Methods-20 VKH patients with acute bilateral panuveitis were studied. 20 healthy adults and 11 Behçet's disease patients with active uveoretinitis served as controls. A $75 \mathrm{~g}$ oral glucose tolerance test (OGTT) was given in the acute stage of ocular inflammation before systemic corticosteroid therapy. The OGTT was repeated in the convalescent stage of VKH disease in the patients with glucose intolerance before treatment. Insulin response was examined at the same time as the OGTT when possible.

Results-55\% of VKH patients (11/20) showed glucose intolerance but no apparent insulin secretion deficiency was detected. Four of seven patients in the convalescent stage showed improvement of glucose tolerance. None of the normal controls or disease controls showed glucose intolerance.

Conclusion-A high incidence of glucose intolerance was found in the acute stage of VKH disease. However, glucose intolerance improved in most cases after systemic corticosteroid therapy. It is possible that glucose intolerance seen in VKH patients may be related to the autoimmune inflammatory process of this disease.

(Brf Ophthalmol 1999;83:39-42)
\end{abstract}

Department of Ophthalmology, Yokohama City University School of Medicine, Yokohama, Japan

N Yawata

S Nakamura

M Kijima

N Ikai

M Kanai

M Sugita

S Ohno

Correspondence to: Professor Shigeaki Ohno, Department of

Ophthalmology, Yokohama City University School of Medicine, 3-9, Fuku-ura, Kanazawa-ku, Yokohama 236, Japan.

Accepted for publication 30 July 1998
Systemic corticosteroids are the mainstay of treatment of Vogt-Koyanagi-Harada (VKH) disease. ${ }^{1}$ However, various adverse effects of this systemic corticosteroid therapy are sometimes observed. ${ }^{2}$ Glucose intolerance has also been reported in several other autoimmune diseases such as rheumatoid arthritis and lupus erythematosus. ${ }^{34}$ Therefore, it is important to evaluate general systemic conditions of patients with $\mathrm{VKH}$ thoroughly before systemic treatment of ocular inflammation.

Advances have been made in the assessment of glucose tolerance and various methods are available to us now. However, in the daily practice of ophthalmology, complicated tests are not always practical. In this study, we utilised simple oral glucose tolerance tests (OGTT) in VKH patients to evaluate their glucose tolerance status before treatment and to assess changes brought about by treatment.
Materials and methods

Twenty new patients with $\mathrm{VKH}$ disease who visited the uveitis survey clinic of the Yokohama City University Hospital from October 1991 to January 1995 were the subjects of this study. There were 14 men and six women with a mean age of 36.4 years ranging from 23 to 51 years. All patients had acute bilateral panuveitis with serous retinal detachment. Fluorescein angiograms showed hyperfluorescein staining in both the early and late stages. Meningeal signs and pleocytosis of the cerebrospinal fluid $(\mathrm{CSF})^{5}$ were seen in all patients. All patients denied a known history of diabetes or hepatic disorder before diagnosis of $\mathrm{VKH}$ disease. None of these patients had received systemic corticosteroid therapy previously.

The control group consisted of normal controls and disease controls. Twenty age matched non-obese healthy adults served as normal controls. Eleven age matched Behçet's disease patients with active uveoretinitis served as disease controls. Most of the Behçet's patients were receiving colchicine, cyclosporin $\mathrm{A}$, or a new immunosuppressive drug, FK506, and some patients received systemic corticosteroids only during severe ocular attacks for a few days. No patient was administered corticosteroids continuously.

\section{PRETREATMENT TESTING OF GLUCOSE}

\section{TOLERANCE}

A 75 g OGTT $^{6}$ was given to all VKH patients before systemic treatment. Following an overnight fast, $75 \mathrm{~g}$ of glucose in flavoured water was given orally within about 5 minutes. Zero time was set at the beginning of intake, blood samples were collected at 0,60 , and 120 minutes, and blood glucose levels of all the samples were measured. Immunoreactive insulin (IRI) ${ }^{7}$ assay was performed using the same samples in eight randomly selected VKH patients. OGTT was performed similarly to the control group.

\section{POST-TREATMENT TESTING OF GLUCOSE}

TOLERANCE

The OGTT was performed again on VKH patients after complete remission of $\mathrm{VKH}$ disease when under no systemic medication. The test was given only to those patients who had shown glucose intolerance in the acute stage of VKH. IRI was measured in the same samples used for the OGTT. The classification of WHO Expert Committee on Diabetes Mellitus, ${ }^{8}$ was adopted as the criterion of glucose intolerance.

\section{ASSESSMENT OF VKH DISEASE}

To evaluate active inflammation of $\mathrm{VKH}$ disease, we estimated the clinical score of ocu- 


\begin{tabular}{|c|c|c|c|c|c|}
\hline Score & 0 & 1 & 2 & 3 & 4 \\
\hline AC flare & - & \pm & $1+$ & $2+$ & $3+$ \\
\hline$A C$ cells & - & \pm & $1+$ & $2+$ & $3+$ \\
\hline KPs & - & & + & & \\
\hline $\begin{array}{l}\text { Nodules of iris } \\
\text { or angle }\end{array}$ & - & & + & & \\
\hline Papilloedema & - & \pm & + & & \\
\hline $\begin{array}{c}\text { Serous retinal } \\
\text { detachment }\end{array}$ & & & & & \\
\hline
\end{tabular}

Figure 1 Clinical score of ocular inflammation in $V K H$ disease. Active inflammation is classified into 5 degrees from score 0 to score 4. AC=anterior chamber; KPs=keratic precipitates.

lar inflammation (Fig 1), such as flare and cells in the anterior chamber and keratitic precipitates. In addition to ocular inflammatory conditions, white blood cell (WBC) count, erythrocyte sedimentation rate (ESR), CRP values, and the number of lymphocytes in the $\mathrm{CSF}$ were measured, to evaluate the condition of systemic inflammation. Body mass index (BMI; body weight $(\mathrm{kg}) /$ height $(\mathrm{m})^{2}$ ) was also considered as a factor affecting glucose tolerance. HLA class II typing was performed on peripheral blood lymphocytes to study the influence of genetical factors. For treatment of $\mathrm{VKH}$ disease, corticosteroid pulse therapy was performed on eight patients, high dose corticosteroid therapy on four patients, and eight patients were given FK506. Corticosteroid pulse therapy was given by intravenous drip infusion of $1000 \mathrm{mg}$ methylprednisolone for 3 days, followed by $40 \mathrm{mg}$ of oral prednisolone. High dose corticosteroid therapy consisted of an intravenous drip infusion of an initial dose of $200 \mathrm{mg}$ prednisolone followed by a gradual decrease. The initial dose of oral FK506 therapy was $0.15 \mathrm{mg} / \mathrm{kg} / \mathrm{day}$.

\section{Results}

The OGTT revealed that, of $20 \mathrm{VKH}$ patients, $11(55 \%)$ had glucose intolerance (Table 1) Two $(10 \%)$ showed a diabetes mellitus (DM) pattern, nine (45\%) an impaired glucose tolerance (IGT) pattern, and nine (45\%) a normal pattern. The IRI assay showed no apparent insulin secretion insufficiency in VKH patients.

On the other hand, both the normal controls and disease controls showed normal OGTT patterns. The OGTT and IRI assay were repeated in the convalescent stage of VKH disease in seven patients who presented with glucose intolerance in the acute stage. These patients were not receiving systemic therapy at this time.

Improvement of glucose tolerance was seen in four patients. These four patients showed an IGT pattern in the pretreatment OGTT, but a normal pattern in the post-treatment OGTT. One patient with a DM pattern in the pretreatment OGTT presented no change in the posttreatment OGTT. Worsening of glucose tolerance was seen in two patients who showed an IGT pattern in the pretreatment OGTT and a DM pattern in the post-treatment OGTT.

The clinical scores of ocular inflammation were higher in glucose intolerance patients than in normal tolerance patients (Table 1). In the glucose intolerance patients, the mean score was 10.2 (SD 3.5) compared with 6.8 (2.4) in normal glucose tolerance patients $(\mathrm{p}<0.05$ by Mann-Whitney U test).

Table 1 Clinical scores of ocular inflammation, BMI, and OGTT results in VKH patients

\begin{tabular}{|c|c|c|c|c|c|c|c|c|c|c|c|}
\hline \multirow{3}{*}{$\frac{\text { Patient }}{1}$} & \multirow{3}{*}{$\begin{array}{l}\text { Sex, age } \\
M, 29 \mathrm{y}\end{array}$} & \multirow{3}{*}{$\begin{array}{l}B M I \\
21\end{array}$} & \multirow{3}{*}{$\frac{\text { Score }^{*}}{4}$} & \multicolumn{4}{|c|}{$\begin{array}{l}\text { OGTT in acute stage }(\mathrm{mg} / \mathrm{dl}) \\
\text { (IRI) }(\mu \mathrm{U} / \mathrm{ml})\end{array}$} & \multicolumn{4}{|c|}{$\begin{array}{l}\text { OGTT in convalescent stage }(\mathrm{mg} / \mathrm{dl}) \\
(I R I)(\mu \mathrm{U} / \mathrm{ml})\end{array}$} \\
\hline & & & & 0 & 60 & $120 \mathrm{~min}$ & & 0 & 60 & $120 \mathrm{~min}$ & \\
\hline & & & & $\begin{array}{l}97 \\
(6\end{array}$ & $\begin{array}{l}133 \\
99\end{array}$ & $\begin{array}{l}144 \\
22)\end{array}$ & IGT & $\begin{array}{l}94 \\
(9\end{array}$ & $\begin{array}{l}115 \\
59\end{array}$ & $\begin{array}{l}100 \\
48)\end{array}$ & NL \\
\hline 2 & $\mathrm{M}, 30$ & 29 & 4 & 95 & 191 & 131 & NL & & & & \\
\hline 3 & $M, 51$ & 26 & 13 & $\begin{array}{l}104 \\
(7\end{array}$ & $\begin{array}{l}214 \\
96\end{array}$ & $\begin{array}{l}125 \\
94)\end{array}$ & $\mathrm{DM}$ & 96 & 235 & 172 & $\mathrm{DM}$ \\
\hline 4 & $\mathrm{~F}, 44$ & 21 & 6 & $\begin{array}{l}97 \\
(10\end{array}$ & $\begin{array}{l}134 \\
45\end{array}$ & $\begin{array}{l}101 \\
92)\end{array}$ & NL & & & & \\
\hline 5 & $\mathrm{~F}, 27$ & 21 & 9 & 94 & 179 & 87 & NL & & & & \\
\hline 6 & M, 38 & 21 & 5 & $\begin{array}{l}95 \\
(4\end{array}$ & $\begin{array}{l}139 \\
53\end{array}$ & $\begin{array}{l}98 \\
23)\end{array}$ & NL & & & & \\
\hline 7 & $M, 43$ & 13 & 13 & $\begin{array}{l}100 \\
(15\end{array}$ & $\begin{array}{l}183 \\
380\end{array}$ & $\begin{array}{l}143 \\
157)\end{array}$ & IGT & $\begin{array}{l}90 \\
(4\end{array}$ & $\begin{array}{l}139 \\
60\end{array}$ & $\begin{array}{l}109 \\
47)\end{array}$ & NL \\
\hline 8 & F, 29 & 18 & 8 & 111 & 88 & 147 & IGT & $\begin{array}{l}86 \\
(5\end{array}$ & $\begin{array}{l}131 \\
72\end{array}$ & $\begin{array}{l}110 \\
74)\end{array}$ & NL \\
\hline 9 & M, 33 & 21 & 14 & $\begin{array}{l}103 \\
(5\end{array}$ & $\begin{array}{l}190 \\
57\end{array}$ & $\begin{array}{l}164 \\
78)\end{array}$ & IGT & $\begin{array}{l}117 \\
(0\end{array}$ & $\begin{array}{l}245 \\
10\end{array}$ & $\begin{array}{l}145 \\
11)\end{array}$ & DM \\
\hline 10 & $M, 51$ & 27 & 15 & $\begin{array}{l}115 \\
(14\end{array}$ & $\begin{array}{l}244 \\
171\end{array}$ & $\begin{array}{l}183 \\
156)\end{array}$ & $\mathrm{DM}$ & & & & \\
\hline 11 & $\mathrm{~F}, 42$ & 22 & 6 & 104 & 176 & 167 & IGT & & & & \\
\hline 12 & $M, 23$ & 18 & 4 & $\begin{array}{l}101 \\
(6\end{array}$ & $\begin{array}{l}119 \\
33\end{array}$ & $\begin{array}{l}125 \\
29)\end{array}$ & NL & & & & \\
\hline 13 & $M, 25$ & 23 & 9 & 102 & 109 & 116 & NL & & & & \\
\hline 14 & $M, 45$ & 25 & 10 & 115 & 180 & 146 & IGT & & & & \\
\hline 15 & $M, 26$ & 22 & 7 & $\begin{array}{l}91 \\
(8\end{array}$ & $\begin{array}{l}129 \\
51\end{array}$ & $\begin{array}{l}93 \\
42)\end{array}$ & NL & & & & \\
\hline 16 & $\mathrm{M}, 32$ & 23 & 8 & 95 & 149 & 147 & IGT & $\begin{array}{l}92 \\
(7\end{array}$ & $\begin{array}{l}172 \\
93\end{array}$ & $\begin{array}{l}137 \\
79)\end{array}$ & NL \\
\hline 17 & $\mathrm{M}, 48$ & 20 & 11 & 92 & 122 & 101 & NL & & & & \\
\hline 18 & $\mathrm{~F}, 24$ & 20 & 7 & 101 & 116 & 137 & NL & & & & \\
\hline 19 & $M, 53$ & 22 & 12 & 100 & 161 & 147 & IGT & $\begin{array}{l}105 \\
(4\end{array}$ & $\begin{array}{l}209 \\
68\end{array}$ & $\begin{array}{l}106 \\
39)\end{array}$ & $\mathrm{DM}$ \\
\hline 20 & $M, 35$ & 23 & 12 & 98 & 189 & 141 & IGT & & & & \\
\hline
\end{tabular}

$\star$ Score $=$ clinical score of ocular inflammation

IGT = impaired glucose tolerance pattern; NL = normal pattern; $\mathrm{DM}=$ diabetes mellitus pattern . 
The average number of lymphocytes in CSF was $452 \times 10^{6} / 1$ in glucose intolerance patients and $438 \times 10^{6} / 1$ in normal tolerance patients; the difference was not significant.

All results in blood tests were within normal limits. There was no correlation between results of blood examinations and glucose tolerance. Mean BMI was 22.4 (SD 2.8) in VKH patients, 22.3 (3.4) in normal controls, and 21.8 (3.1) in the disease controls, showing no significant difference ( $p>0.05$ by MannWhitney U test).

As for HLA class II typing, $18(90 \%) \mathrm{VKH}$ patients presented with HLA-DR4, HLADR53, and HLA-DQ4 in agreement with results of previous reports. ${ }^{9}$

\section{Discussion}

In this study, $55 \%$ of newly diagnosed $\mathrm{VKH}$ patients showed glucose intolerance compared with none in the control groups. Modes of likely causes of glucose intolerance in these VKH cases were considered.

Glucose intolerance can be largely grouped by aetiology into two categories-IDDM/ NIDDM and other causes. In IDDM/NIDDM cases, insulin secretion is often decreased due to damage to pancreatic islet $\beta$ cells. ${ }^{7}$ In comparison, decreased peripheral insulin sensitivity can also bring about glucose intolerance..$^{11}{ }^{11}$ In the latter case, insulin secretion can be preserved. In this study, no apparent insufficiency of insulin secretion was observed in cases with glucose intolerance in the acute stage suggesting that the mode of glucose intolerance may be by way of decreased peripheral sensitivity to insulin.

In previous studies of $\mathrm{VKH}$, cytotoxic $\mathrm{T}$ cells against melanocytes have been reported. ${ }^{12}$ Cytotoxic T cells have been considered as a key agent in injury of pancreatic $\beta$ cells in IDDM, also in autoimmune disease. ${ }^{13}$ Furthermore, in view of HLA typing, correlation between VKH and HLA-DR4 has been well established. ${ }^{9}$ In turn, $80 \%$ of IDDM cases also present with HLA-DR $4 .{ }^{14}$ Although there may be a difference in states of insulin secretion between the acute stage of VKH and IDDM, there is the above mentioned pathological similarity, and there is still space for further research in pathogenesis of glucose intolerance which may be in common to the two diseases. Under the influence of a similar genetic background, there may be a tendency for activation of cytotoxic $\mathrm{T}$ cells to various target antigens.

Previously, there has been one case report of VKH disease with IDDM. ${ }^{15}$ In the report, it was speculated that some processes alter cell surface components both in melanocytes and pancreatic $\beta$ cells leading to endocrine disturbance. However, at present, there is no clear evidence that these cytotoxic $\mathrm{T}$ cells recognise the same antigens in VKH and IDDM.

Glucose intolerance has been associated with several other autoimmune diseases. Intolerance seen in rheumatoid arthritis (RA) has been reported to improve after corticosteroid therapy and when severe inflammation has been controlled. ${ }^{3}$ It has been suggested in this report that glucose intolerance in active RA is related to insulin resistance. This and other studies have reported peripheral insulin resistance to exist in inflammatory reactions in general. ${ }^{10}{ }^{11}$

Various cytokines are acting in inflammatory disease.

Interferons (IFN) and interleukin 1 (IL-1) have been reported to stimulate secretion of counterregulatory hormones of blood glucose homeostasis (cortisol, growth hormone). ${ }^{16-19}$ Furthermore, IFN has been reported to reduce peripheral insulin sensitivity. ${ }^{16}$ High levels of serum IFN have also been reported in $\mathrm{VKH} .{ }^{20}$ Our patients with severe ocular inflammation tended to develop glucose intolerance without impaired insulin secretion in the acute phase of $\mathrm{VKH}$ disease, suggesting some role for these cytokines in bringing about intolerance to glucose.

We attempted to confirm this finding by comparing results with cases of Behçet's disease which is also a systemic inflammatory disease. Similar to VKH disease, high production of IFN- $\gamma$ has been reported in this disease. ${ }^{21}$ In our study, glucose intolerance was not proved in any of the patients with Behçet's disease during active ocular inflammation. Comparison of results in VKH and Behçet's diseases suggest that IFN may not be playing a key role in inducing glucose intolerance.

In other autoimmune diseases with glucose intolerance such as systemic lupus erythematosus, high levels of serum anti-insulin receptor antibodies have been reported. ${ }^{4}$ As our results suggest decreased peripheral sensitivity to insulin in VKH patients, presence of such autoantibodies could be considered. In VKH disease, although antiretinal autoantibodies have been reported, ${ }^{22}$ existence of other antibodies affecting glucose tolerance is yet to be proved.

In this study, worsening of glucose intolerance was seen in two cases. It may be that these patients had had glucose intolerance before they developed VKH disease and systemic corticosteroid therapy had worsened their glucose intolerance. It may be stressed that thorough evaluation of systemic conditions of $\mathrm{VKH}$ patients is important.

We believe further studies to clarify mechanisms of glucose intolerance in VKH may in turn lead to new findings in the autoimmune mechanism and pathogenesis of this disease.

1 Sasamoto Y, Ohno S, Matsuda H. Studies on corticosteroid therapy in Vogt-Koyanagi-Harada disease. Ophthalmologica 1990;201:162-7.

2 Kumagai A, Morimoto Y, Yamamura Y. Major side effects of glucocorticoids in Japan. Endocrinol fpn 1965;12:36-46

3 Svenson KLG, Pollare T, Lithell $\mathrm{H}$, et al. Impaired glucose handling in active rheumatoid arthritis: relationship to peripheral insulin resistance. Metabolism 1988;37:125-30.

4 Tsokos GC, Gorden P, Antonovych T, et al. Lupus nephritis and other autoimmune features in patients with diabetes mellitus due to autoantibodies to insulin receptor. Ann Intern Med 1985;102:176-81

5 Beniz J, Forster DJ, Lean JS, et al. Variations in clinical features of the Vogt-Koyanagi-Harada syndrome. Retina 1991;11:275-80.

6 Davidson JK, Delcher H, Davidson P. Classification and diagnosis of diabetes mellitus and other categories of glucose intolerance. Diabetes 1979;28:1039-57.

7 Yalow R, Berson S. Plasma insulin concentration in nondiabetic and early diabetic subjects. Diabetes 1960;9:254-60.

8 WHO Expert Committee on Diabetes Mellitus. Second report. Tech Rep Ser 646, Geneva: WHO, 1980:9-14. 
9 Shindo Y, Ohno S, Yamamoto T, et al. Complete association of the HLA-DRB $1^{\star} 04$ and DQB1 ${ }^{\star} 04$ alleles with VogtKoya

10 Beisel WR. Metabolic response to infection. Annu Rev Med 1975;26:9-19.

11 Drobny EC, Abramson EC, Baumann C. Insulin receptors in acute infection: a study of factors conferring insulin resistance. F Clin Endocrinol Metab 1984;58:710-16.

12 Maezawa N, Yano A, Taniguchi M, et al. The role of cytotoxic $\mathrm{T}$ lymphocytes in the pathogenesis of VogtKoyanagi-Harada disease. Ophthalmologica Basel 1982;185 $179-86$.

13 Bordignon PP, Lang R, Endert PM, et al. Cytotoxic T cells specific for glutamic acid decarboxylase in autoimmune diabetes. F Exp Med 1995;181:1923-7.

14 Todd JA. Genetic control of autoimmunity in type 1 diabetes. Immunol Today 1990;11:122-9.

15 Jaggarao N, Voth D, Jacobsen J. The Vogt-Koyanagi-Harada syndrome:association with hypothyroidism and diabetes syndrome:association with hypothyroidis
mellitus. Postgrad Med $\mathcal{f} 1989 ; 65: 587-8$.
16 Koivisto VA, Pelkonen R, Cantell K. Effect of interferon on glucose tolerance and insulin sensitivity. Diabetes 1989;38: 641-7.

17 Rey AD, Besedovsky H. Interleukin 1 affects glucose homeostasis. Am f Physiol 1987;253:794-8.

18 Besedovsky HO, Rey AD. Metabolic and endocrine actions of interleukin-1. Ann NY Acad Sci 1990;594:214-21.

19 Rey AD, Besedovsky HO. Metabolic and neuroendocrine effects of pro-inflammatory cytokines. Eur $\mathcal{f}$ Clin Invest 1992;22 suppl 1:10-5.

20 Ohno S. Immunological aspects of Behçet's and VogtKoyanagi- Harada's diseases. Trans Ophthal Soc UK 1981; 101:335-41

21 Ohno S, Kato F, Matsuda H, et al. Studies on spontaneous production of gamma-interferon in Behçet's disease. Ophthalmologica 1982;185:187-92.

22 Chan CC, Palestine AG, Nussenblatt RB, et al. Anti-retinal auto-antibodies in Vogt-Koyanagi-Harada syndrome, Behçet's disease, and sympathetic ophthalmia. Ophthalmology 1985;92:1025-8. 